\title{
DOENÇAS TRANSMISSÍVEIS E ISOLAMENTO: A PERCEPÇÃO DE ALUNO DE ENFERMAGEM
}

\author{
Tokico Murakawa Moriya* \\ Elucir Gir* \\ Edna Paciência Vietta ${ }^{\star}$ \\ Milca Severino Pereira**
}

MORIYA, T.M. et al. Doenças transmissíveis e isolamento: a percepça de aluno de enfermagem. Rev.Esc.Enf.USP, v.29, n.3, p. 286-96, dez. 1995.

As Doenças Transmissiveis (DT) carregam consigo, desde épocas remotas, estigma vinculado à marginalização. Objetivamos detectar, entre alunos de graduação de enfermagem, a percepção que os mesmos têm acerca de DT' e Isolamento, bem como sua expectativa em atuar em unidades onde são atendidos pacientes com D'T e que necessitam de isolamento. Aplicamos um questionário previamente validado por 3 juizes ligados à área de DT. Detectamos que persistem ainda conceitos esteriotipados bastante negativos sobre o portador de I'T e Isolamento, e poucos alunos escolheriam a Unidade de DT' como local de trabalho. O conhecimento prévio dos conceitos que os estudantes têm acerca de DT e Isolamento é importante a fim de, durante o curso, reforçar os aspectos positivos detectados e trabalhar com os negativos de forma a prepará-los para prestar assistência de enfermagem efetiva, levando-se em consideração os medos e preconceitos.

Unitermos: Doenças Transmissiveis, Isolamento, Alunos de Fnfermagem.

\section{INTRODUÇÃO}

As doenças transmissiveis (DT) carregam consigo, desde épocas remotas, estigma vinculado à marginalização. Está descrito na Bíblia - Antigo Testamento - como orientação de Moisés à Aarão que "todo homem atingido de lepra terá suas vestes rasgadas e a cabeça descoberta, cobrirá a barba e clamará: Impuro! Impuro! Enquanto durar o mal ele será impuro. E, impuro habitará só, e a

\footnotetext{
* Enfermeira. Docente da Escola de Enfermagem de Ribeirăo Preto-USP. Centro Colaborador da Organização Mundial da Saúde para o Desenvolvimento da Pesquisa em Enfermagem.

** Enfermeira. Docente da Faculdade de Enfermagem e Nutrição da Universidade Federal de Goiás. Ex-aluna do Curso de Doutorado da EERP-USP.
} 
habitação será fora do acampamento" (LEVÍTICO, 1962). Está descrito, ainda, que "... deverão ser expulsos os homens atacados de gonorréia..." (NÚ MEROS, 1962).

Durante a epidemia da pesta do seculo XVIIl todas as pessoas consideradas como fonte de infecção da doença eram removidas para um local onde pudessem vir a se recuperar ou morrer e aquelas que tivessem cuidado das mesmas deveriam ficar isoladas por 10 dias (DUBAY; GRUBB, 1973).

Ainda segundo esses autores, os médicos "corajosos" dessa época, para cuidarem dos doentes usavam capacetes, roupões compridos, luvas pesadas e suas faces eram protegidas com óculos e respiradores semelhantes a um longo bico preenchido com ervas aromáticas.

Podemos notar nesses condutas mencionadas aspectos positivos de medidas de higiene, os quais poderiam conter algumas noções de transmissao de doenças, todavia, exibem uma rigidez muito grande de comportamento.

Envolvidos em atividades de ensino, pesquisa e serviço de extensão à comunidade, os autores deste trabalho têm notado a persistência de preconceitos e estigmas sobre DT e isolamento, inclusive entre profissionais da área da saúde.

$\mathrm{O}$ isolamento de pessuas portadoras de $\mathrm{DT}$, como já referido anteriormente, é de épocas muito remotas. O isolamento de D'T em hospitais surgiu inicialmente na Idade Média para abrigar leprosos.

E o isolamento do paciente visando impedir a disseminação da doença, só ocorreu mais tarde no século XVIII, por volta de 1745 quando foi fundado na Inglaterra, um hospital para atendimento a pacientes com varíola e um ano depois para abrigar portadores de doenças venéreas (MELLO, 1961).

$\mathrm{O}$ embasamento cientifico para as IT começou a surgir e se firmar, por volta de 1870, na França, graças aos experimentos de Pasteur sobre a fermentação e o desenvolvimento da teoria da infecção, baseada na presença de microorganismos. Grancher, em 1890, apoiado nas descobertas de Pasteur, veio demonstrar o valor das técnicas assépticas nas unidades de DT, em hospital geral. Já naquela época os doentes portadores dessas enfermidades eram isolados dos demais por meio de biombos e todos que entrassem em contato com esses pacientes deveriam fazer uso de aventais c ao sair da área isolada deveriam retira-los, bem como lavar as mãos e passar em seguida uma solução antisséptica (MELLO, 1961).

O primeiro hospital edificado especificamente para tratamento de D'T de qualquer natureza foi o Iospital Pasteur, na França, em 1900. Neste hospital, os quartos já eram individuais e as enfermarias subdivididas em compartimentos, onde permaneciam os convalescentes; as técnicas assépticas eram ali observadas rigorosamente.

Nesse breve resumo historico, pode-se verificar que a prática de isolamento em DT em hospitais gerais ou especializados foi, desde a Idade Média se cristalizando, persistindo até os dias de hoje. A compreensão de tais doenças, 
modificada através dos tempos, vem acompanhando a evolução da sociedade e dos conhecimentos técnico-científicos, impondo-se revisões e reformulações de novos conceitos.

Os conceitos ou estruturas conceituais adquiridas ao longo desta evolução determinam as atitudes dos indivíduos de modo geral no exercício da prática dos profissionais de saúde, estabelecendo-se procedimentos consensuais e, portanto ações de saúde coerentes e apropriadas para $o$ atendimento.

A ORGANIZAÇÃO PANAMERICANA DE SAÚDE/ORGANIZAÇÃO MUNDIAL DA SAÚDE-OPS/OMS (1983) define doença transmissivel como "doença causada por um agente infeccioso e/ou suas toxinas através da transmissão desse agente ou seus produtos, do reservatório ou de uma pessoa infectada ao hospedeiro suscetivel, quer diretamente de uma pessoa ou animal infectado quer indiretamente, por meio de um hospedeiro intermediário vegetal ou animal, por meio de um vetor, ou através do meio ambiente inanimado". Com base neste conceito definem Isolamento como "a separação de pessoas ou animais infectados, durante o período de transmissibilidade da doença, em lugar e condições que previnam ou limitem a transmissão direta ou indireta do agente infeccioso a indivíduos suscetive is ou que o possam transmitir a outros".

$\mathrm{Na}$ definição acima citada fica evidente que o propósito básico do isolamento 6 confinar o agente infeccioso a uma área restrita até que o perigo de propagação tenha deixado de existir. Ocorre, no entanto, com freqüencia, o "isolamento" do paciente, esquecendo-se que o indesejável é o agente infeccioso e não o seu portador.

As téenicas e os procedimentos adotados em unidades de isolamentos de DT para a prevenção e controle da disseminação do agente infeccioso, tais como uso do avental, luvas, máscaras, gorro, lavagem das mãos não constituem inovação, como pode-se perceber atraves do que foi descrito anteriormente.

Até mais ou menos a década de 60 , o isolamento de pacientes com D'T não era sistematizado com base nos seus aspectos epidemiológicos, usando-se técnicas e procedimentos uniformizados a todos os tipos de ITT.

Numa tentativa de reorganizar as medi las preventivas, o CENTER FOR DISEASE CONTROL-CDC (1970), com base em alguns aspectos epidemiológicos das DT, propuseram cinco tipos de isolamentos: isolamento perigoso, isolamento respiratório, isolamento protetor, precauções entéricas, precauções com lesões cutâncas. Cada tipo de isolamento apresenta finalidade especifica e requer precauçōes próprias.

A sistematização dos tipos de isolamento trouxe vários benefícios, tais como: facilidades de atuação dos profissionais da área, economia à instituição uma vez que equipamentos de proteção individual deixaram de ser usados de forma indiscriminada, servindo apenas para o cumprimento de um ritual. Atualmente a orientação do CDC, no tocan te aos tipos de isolamento é adotada quase que de maneira universal. 
Com o surgimento da AIDS, os CENTERS FOR DISEASE CONTROL(CDC) publicou em 1987 as Precauções Universais, com ênfase nos cuidados com sangue e fluídos corporais.

Envolvidos em atividades de ensino, pesquisa e serviço de extensão à comunidade, os autores deste trabalho têm notado a persistência de preconceitos e estigmas sobre DT $e$ isolamento inclusive entre profissionais da área de saúde.

Tendo em vista esses aspectos das DT e isolamento, e o ensino prático da disciplina de Enfermagem em Doenças Transmissíveis da Escola de Enfermagem de Ribeirão Preto - Universidade de São Paulo ser realizado em unidade de internação especifica para DT, as autoras se propuseram a realizar o presente trabalho, com o objetivo de detectar entre alunos de graduação, que iniciam a Disciplina de Enfermagem em Doenças Transmissíveis, a percepção que os mesmos têm acerca das DT e do isolamento, bem como sua expectativa em atuar em unidades onde são atendidos pacientes com DT e que necessitem de isolamento.

O conhecimento prévio dos conceitos que os estudantes têm acerca de DT' e isolamento é importante a fim de, durante o curso, reforçar os aspectos positivos detectados e trabalhar com os negativos de forma a prepará-los para prestar assistência de enfermagem efetiva, levando-se em consideração os medos e preconceitos.

\section{METODOLOGIA}

Para a realização do presente estudo foi aplicado um questionário aos alunos regularmente matriculados no 4o. semestre letivo de 1992, no curso de graduação em enfermagem da EERP-USP, uma semana antes de iniciarem a Disciplina de Enfermagem em Doenças Transmissiveis. O critério de inclusão, dos alunos, neste estudo, foi estar presente no dia e hora da aplicação do questionário, a qual foi realizada em uma única vez.

O questionário, com três perguntas abertas, passou por validação prévia, tendo sido submetido a apreciação de três juízes, ligados à área de DT a fim de avaliarmos a inteligibilidade das questões e realização de adequações necessárias. $\Lambda$ s questões foram as seguintes:

1. Qual é o seu conceito sobre portador de DT?

2. Qual é o seu conceito sobre isolamento de D'T?

3. Você trabalharia em unidade de DT? Por que?

Para análise das questões os dados foram mapeados, agrupando os enfoques similares. 


\section{RESULTADOS E DISCUSSÃO}

De um grupo constituído de 80 alunos, $75(93,75 \%)$ participaram da presente investigação.

A primeira questão formulada aos alunos foi descrever seus conceitos em relação ao portador de DT. As respostas obtidas estão apresentadas na Tabela 1.

Tabela 1 - Distribuição dos alunos segundo seus conceitos de pessoa portadora de D'T. Ribeirão Preto, 1992.

\begin{tabular}{|c|c|c|}
\hline CONCEITO & $\mathbf{f}$ & (\%) \\
\hline $\begin{array}{l}\text { - Pessoa com maior risco de transmitir a doença e que necessita } \\
\text { de cuidados específicos em isolamento (técnicas rigorosas; apoio } \\
\text { emocional; orientação; segurança e cuidados fisicos) } \\
\text { - Pessoa triste; preocupada; nervosa; carente; envergonhada; } \\
\text { apática; desconfiada; solitária; angustiada; limitada; revoltada; } \\
\text { marginalizada; repelida; agredida física e espiritualmente } \\
\text { - Pessoa que deve ser isolada do convivio social; deixada de lado; } \\
\text { que coloca em risco a vida das pessoas } \\
\text { - Pessoa com maus hábitos alimentares e higiênicos; vítima do } \\
\text { analfabetismo } \\
\text { - Não emitiu conceito }\end{array}$ & $\begin{array}{l}12 \\
08 \\
04 \\
03\end{array}$ & $\begin{array}{r}(16,0) \\
(10,7) \\
(5,3) \\
(4,0)\end{array}$ \\
\hline TOTAL & 75 & $(100,0)$ \\
\hline
\end{tabular}

Analisando a Tabela 1 podemos notar que um número significativo de estudantes $(64,0 \%)$ percebe o portador de $\mathrm{D}^{\prime} \mathrm{T}$ como aquele com maior risco de transmissão da doença, requerendo cuidados espećfícos em isolamento, envolvendo ações não so "instrumentais" (procedimentos, têcnicas) como também "expressivas" (afetivo-emocionais), conforme mencionados por GIR; MORIYA (1991). Esse conceito parece demonstrar desconhecimento de que nem todas as DT são contagiosas e, portanto, o isolamento não deve ser uma regra geral.

Conceitos estereotipados vinculados à marginalização ficaram bem evidenciados em $10,7 \%$ dos alunos quando estes se referiram ao portador de DT como pessoa que deve ser isolada do convívio social; deixada de lado; que 
coloca em riso a vida das pessoas. Provavelmente, em razão desse mesmo conceito $16,0 \%$ dos alunos percebem o portador de IT, como pessoa triste; preocupada; nervosa; carente; envergonhada; apática; desconfiada; solitária; limitada; angustiada; revoltada; marginalizada; repelida; agredida física e espiritualmente.

Outras percepções em relação ao portador de DT é de pessoa com maus hábitos alimentares e higiênicos; vítima da analfabetização (5,3\%). Estes conceitos demonstram uma visão pouco abrangente dos estudantes, sobre 0 processo Saúde-Doença, atribuindo a D'T a causas especificas e limitadas.

Quanto ao conceito de isolamento, a maioria (60.0\%) dos alunos o percebe como um local fechado, com alto risco de transmitir e/ou contrair doença e que exige cuidados e técnicas especiais (Tabela 2).

Tabela 2 . Distribuição dos alunos segundo seus conceitos de isolamento. Ribeirão Preto, 1992.

\begin{tabular}{|c|c|c|}
\hline CONCEITO & $\mathbf{f}$ & $(\%)$ \\
\hline $\begin{array}{l}\text { - Local fechado, com alto risco de contrair e/ou transmitir doença, } \\
\text { que exige cuidados e técnicas especiais } \\
\text { - Lugar desagradável; sujo; tedioso; triste; solitário; sombrio; } \\
\text { negativo; monótono; cheio de micróbios; prisão; que não se pode } \\
\text { receber visitas; desagradável para trabalhar; com ar rarefeito; } \\
\text { pesado e tenso } \\
\text { - Local altamente higiênico, limpo para não se contaminar; onde se } \\
\text { usa material descartável; onde todos os pertences devem ser } \\
\text { lavados separadamente } \\
\text { - Local onde a assistência nunca é feita adequadamente pela } \\
\text { negligência de pessoas não treinadas } \\
\text { - Não emitiu conceito }\end{array}$ & $\mid \begin{array}{l}02 \\
07\end{array}$ & $\begin{array}{r}(6,7) \\
(2,7) \\
(9,3)\end{array}$ \\
\hline TOTAL & 75 & $(100,0)$ \\
\hline
\end{tabular}

Esse conceito vai ao encontro da definição da Organização Panamericana de Saúde (OPAS) e Organização Mundial de Saúde (OMS) que definem o isolamento como "a segregação de pessoas infectadas, durante o período de transmissibilidade da doença, em local com condições para evitar a transmissão direta ou indireta do agente infeccioso a indivíduos suscetíveis, ou que possam transmitir a outros" (OMS/OPAS, 1983). 
Na definição da OPAS/OMS pode-se notar ausência de enfoque assistencial. No entanto, o mesmo parece não ocorrer na percepção do estudante, estando esta mais identificada com o conceito de isolamento de DT formulado por MORIYA; MANZOLI, (1986), ou seja: "é a situação ambiental em que estímulos oferecidos aos pacientes são pouco freqüentes e, neste caso, são poucas as oportunidades para que ele venha a emitir suas respostas operantes, importantes para manter seu equilíbrio psico-social, ao mesmo tempo é uma situação que elicia respostas respondentes, de cunho emocional".

A preocupação com o aspecto assistencial é evidente na Tabela 1, quando um grupo de estudantes $(64,0 \%)$ se referem ao portador de DT como sendo "pessoa... que necessita de cuidados especiais, ou seja: apoio emocional, paciência, orientação, segurança e cuidados físicos, além de técnicas especiais".

$\mathrm{O}$ isolamento é também tido por $21,3 \%$ (16) dos estudantes como um lugar desagradável; sujo; tedioso; triste; sombrio; solitário; negativo; monótono; cheio de micróbios; prisão; que não se pode receber visitas; desagradável para se trabalhar; com ar rarefeito, pesado e tenso.

As respostas desses alunos são carregadas de conotaçōes negativas e nos faz lembrar as descrições de isolamento apresentadas em livros de literatura ou em filmes históricos que retratam locais onde eram mantidas as pessoas indesejáveis a sociedade ou que colocavam $\mathrm{em}$ risco a vida de outras pessoas.

Um outro grupo de alunos $(6,7 \%)$ visualiza o isolamento como um local altamente higiênico, limpo para não se contaminar; onde se usa material descartável; onde todos os pertences devem ser lavados separadamente. Fica demonstrado aqui, também o preconceito em relação ao isolamento e paciente portador de DT, onde aspectos puramente técnicos são lembrados e reforçados por imagens idealizadas.

Dois alunos referiram-se ao isolamento como um local onde a assistência nunca é feita adequadamente pela negligência de pessoas não treinadas. Esse conceito de falta de assistencia pode snr proveniente da midia que freqüentemente expõem ao público uma visão de assistência à saúde extremamente deficitária, em nosso país.

Quando perguntado aos alunos se trabalhariam numa unidade de Doenças Transmissiveis apenas $4(5,3 \%)$ responderam positivamente, 44 $(58,7 \%)$ responderam negativamente e $27(36,0 \%)$ referiram não saber ou depende (Tabela 3 ). 
Tabela 3 - Distribuiçāo dos alunos segundo aceitação e motivo para trabalharem cm unidade de DT. Ribeirão Preto, 1992.

\begin{tabular}{|l|lc|}
\hline \multicolumn{1}{|c|}{ CONCEITO } & f & (\%) \\
\hline - SIM & 4 & $(5,3)$ \\
Motivo: & 2 & \\
não há risco de contaminação \\
todo paciente merece igual atenção & 2 & \\
& & \\
- NÃO & 44 & $(58,7)$ \\
Motivo: & & \\
não se julga pessoa forte e corajosa; tem medo de adquirir e/ou \\
transmitir doença; tem preconceito & 31 & \\
a unidade é estressante, angustiada & 5 & \\
prefere trabalhar em outra área & 5 & \\
trabalharia só por imposição & 3 & \\
DEPENDE/NÃO SABE & 27 & $(36,0)$ \\
Motivo: & 20 & \\
não teve experiência & 4 & \\
trabalharia em qualquer área & 3 & \\
dependeria das condições de trabalho e remuneração & & \\
\hline \multicolumn{1}{|c|}{ TOTAL } & 75 & $(100,0)$ \\
\hline
\end{tabular}

Não se espera que todos os alunos optem por trabalhar em unidade de DT, pois existem as preferências individuais, que são extremamente salutares. Outro aspecto a ser considerado dì respeito a não recomendação do Ministério da Saúde, de construção de unidades específicas de isolamento, orientando a previsão de um quarto destinado a portadores de DT para cada 40 leitos, em todas as enfermarias (BRASIL, 1985). O que se destacou na questão foi a razão porquê não aceitariam trabalhar numa unidade de DT. Dentre os 44 estudantes que responderam "não", apenas 5 justificaram que "preferem outra área". Os demais (39) colocaram como razões aspectos vinculados a préjulgamentos negativos em relação ao paciente e unidade de DT: "Não se julga pessoa forte e corajosa"; "tcm medo de adquirir e/ou transmitir doença"; "tem preconceito": "a unidade o estressante, angustiante", "trabalharia por imposição".

Essas respostas, bem como as demais, aqui expostas, mostram que conceitos estigmatizados ainda persistem na atualidade em relação às DT. E 
bem verdade que o presente estudo foi realizado numa pequena amostra de estudantes de enfermagem, mas na realidade reflete parte dos conceitos vigentes na comunidade.

Embora este estudo não nos permita generalizações, entendemos que conceitos de conotações negativas comc estes, aqui representados, podem estar refletindo no entendimento do próprio enfermeiro em suas concepções sobre a enfermagem, por ser uma profissão que como as demais, seus trabalhadores se expõem a riscos ocupacionais.

As atitudes - respostas regularmente favorácis ou desfavoráveis a objetos sociais - se desenvolvem a partir das experiências; são aprendidas através de processos de condicionamento clássico e operante e também da aprendizagem social e da modelação efetuada pelos pais, mestres e companheiros (GOLDSTEIN, 1983). Portanto, as atitudes evoluem constantemente e podem ser modificadas.

Em se tratando de atitudes frente ao portador de DT e Isolamento temos que atuar para que conceitos de conotações negativas que constituem barreiras, sejam substituídos por outros que contribuam efetivamente para intervençōes mais humanas.

\section{CONSIDERAÇÕES FINAIS}

Os resultados apresentados evidenciam (jue, os conceitos de portador de DT e Isolamento são carregados de componentes emocionais, entro estudantes. antes de cursarem a disciplina de Enfermagem em DT.

Entende-se que o profissional de Enfermagem deve ser preparado para desempenhar atividades de natureza inst rumental e expressiva como apontam GIR; MORIYA (1991) e com capacidade crítica de modo a contribuir com ações efetivas, junto aos portadores de D'T. 'Torna-se clara a necessidade de se oferecer ao futuro profissional oportunidades para que possa expressar seus sentimentos e emoçōes no sentido de trabalhar os conceitos em suas diversas conotações, com vistas a mudanças de atitude.

Faz-se necessário atuar junto ao aluno para que conceitos de conotações depreciativas sejam substituidos por outros menos carregados de esterétipos e preconceitos. S6 assim, os alunos, futuros profissionais poderão atuar junto ao paciente com D'T numa interação mais humana e consciente e serem capazes de lidar com suas emoçōes e preconceitos.

Outro aspecto importante a ser focalizado neste curso é a necessidade de adoção de precauções universais na assistência não só ao portador de $1 \mathrm{D}^{\prime} \mathrm{T}$ diagnosticada, mas com todos os pacientes, pois muitos indivíduos podem estar infectados e serem assintomáticos. 
MORIYA, T.M. et ai. Communicable Diseases and isolation: the undergraduation students' perception . Rev.Esc.Enf.USP, v.29, n.3, p. 286-96, dec. 1995

The Communicable Diseases have been associated to stigma and segregation for a long time. This investigation was carried out in order to detect the undergraduation students' perception concerning communicable diseases and isolation, as well as their expectation in working at isolation units. A questionnaire was elaborated and then validated by 3 referees. We allested that some of these students have stereotyped and negative conotations concerning the bearer of such diseases and isolation. Just a few of them mentioned that they would choose this specific unit as the workplace. It is important for us, professors, to know their previous knowledgement about the concepts of communicable diseases and isolation, so that we can reinforce the positive features and work with the negative ones during the courses. It can contribute to prepare these students to give an effective nursing care without fears and stigmas.

UNITERMS: Communicable Disease. Isolation. Nursing Students.

\section{REFERÊNCIAS BIBLIOGRÁFICAS}

BRASIL. Ministério da Saúde. Manual de controle de infecçăo hospitalar. Brasília; Centro de documentaçáo do Ministério da Saúde, 1985.

CENTER FOR DISEASE CON'T'ROL. Isolation Techniques for use in hospitals. 2a. ed. Atlanta. Department of Health Education and Welfare, 1970.

CENTERS FOR DISEASE CONTROL. Morbidity and Mortality Weekly Report. v.35(Supp.). n.5, 1987.

DUBAY, E.C.; GRUBB, R.I. Infection, prevention and control. Saint Lows, Mosby Company, 1973

GIR, E.; MORIYA T.M. O papel da enfermeira, do auxiliar de enfermagem e do atendente de enformagem na assisténcia ao paciente em isolamento de doenças transmissíveis.

Rev. Esc. Enf. USP, v.25, n.3, p. 271-86, 1991.

GOLDSTEIN, J.H. Psicologia social. Rio de Janeiro, Guanabara Dois, 1983.

LEVITICO: Lepra humana modos por que se manifesta. In: BlBLIA Sagrada. Sao Paulo, Ave Maria, 1962. Cap.13, versículos 45,46, p.136.

MELLO, F.V. Linidade de moléstias infecto-contagiosas. Rev. Paul. Hosp., v.9, n.1, p. 13-8, 1961 .

Rev.Esc.Enf.USP, v.29, n.3, p.286-96, dez. 1995. 
MORIYA, T.M.; MANZOLLI, M.C. Isolamento em doenças transmissiveis: conccituação em enfermagem. Rev. Esc. Enf. USP, v.20, n.2, p. 89-100, 1986,

NÚMEROS: as pessoas impuras afastadas do acompanhamento. In: BÍBLIA Sagrada. São Paulo, Ave Maria, 1962. cap.5, versículos 2.3, p. 162.

ORGANIZAÇAO PANAMERICANA DE SAÚDE/ORGANIZAÇAO MUNDIAL, DA SAÚJDE. Controle das doenças transmissíveis no homem. 13 ed. México, 1983.

(Publ. Científica n. 442) 